\title{
PAPER AND ORIGINALS
}

\section{Mesentericocaval "Jump" Graft in Management of Portal Hypertension : Experience with 24 Cases}

\author{
MARTIN SMITH, R. J. TUFT, A. R. DAVIDSON, J. W. LAWS, J. L. DAWSON, \\ ROGER WILLIAMS
}

British Medical fournal, 1974, 3, 705-708

\begin{abstract}
Summary
A series of 24 patients with cirrhosis have undergone mesentericocaval shunt operations for the relief of portal hypertension. Overall the results have been satisfactory. Four of the five patients treated as an emergency and 17 of the 19 who had the operation two to six weeks after haemorrhage had been controlled left hospital alive and well. Separation of the patients into three categories according to the findings of clinical and biochemical tests, however, showed that subsequent survival was satisfactory for patients in categories $A$ and $B$ but that all four patients in category $C$ had died within one year after surgery. Assessment at three months showed that in three patients moderate hepatic encephalopathy had developed.

Evidence that the shunt remains patent was shown by a low incidence of repeated gastrointestinal haemorrhage and a marked diminution in variceal size in $\mathbf{1 8}$ of the 19 cases examined serially. Radiographic techniques for confirming shunt patency were compared and cannulation of the graft via the femoral vein was found to provide a reliable and rapid means of assessment.
\end{abstract}

\section{Introduction}

The diversion of portal blood into the systemic circulation by means of a portacaval shunt has been shown to diminish greatly the risks of recurrent haemorrhage from oesophageal

King's College Hospital, London SE5 8RX

MARTIN SMITH, M.B., M.R.C.P., Senior Registrar, Liver Unit (Present

appointment: Consultant Physician, St. Luke's Hospital, Guildford)

R. J. TUFT, M.B., B.S., House Physician, Liver Unit

A. R. DAVIDSON, M.B., M.R.C.P., Registrar, Liver Unit

J. W. LAWS, F.R.C.P., F.F.R., Consultant Radiologist

J. L. DAWSON, M.S., F.R.C.S., Consultant Surgeon

ROGER WILLIAMS, M.D., F.R.C.P., Consultant

Physician and Director of Liver Unit varices (Jackson et al., 1971). The benefits of this procedure to the patient with cirrhosis, however, are offset by the high operative mortality in those with poor liver function before surgery (Turcotte et al., 1969) and the development of severe hepatic encephalopathy in a significant proportion of cases (Callow et al., 1970). Efforts have therefore been made to develop shunts producing a lower incidence of encephalopathy-for example, the distal splenorenal shunt described by Warren et al. (1967)-but this can be technically difficult and is applicable to relatively few patients. Drapanas (1972) described a side-to-side shunt using a Dacron graft interposed between the superior mesenteric vein and the inferior vena cava. This was claimed to be a relatively simple operation with a low operative mortality even in poor-risk patients $(8 \%)$ and no increase in hepatic encephalopathy for up to three and a half years after surgery.

In view of these encouraging results we have used this procedure, usually known as the mesentericocaval (mesocaval) "jump" graft, in place of the standard portacaval shunt operation during the past 18 months, and we describe here the results obtained in 24 patients with cirrhosis who had been admitted to hospital with bleeding from oesophageal varices.

\section{Patients}

The 24 patients (17. men and 7 women) were aged 29 to 72 years and had a mean age of 48 years. The diagnoses were alcoholic cirrhosis (10 cases), cryptogenic cirrhosis (5), active chronic hepatitis (5), primary biliary cirrhosis (3), and haemochromatosis (1) (table I).

In every case the site of bleeding was confirmed by fibreendoscopic examination. If bleeding continued after admission to hospital it was initially controlled by a Sengstaken-Blakemore tube kept in place for 24 to 48 hours or by oesophageal transection in one case. Subsequently 19 of the patients had an elective mesocaval shunt operation two to six weeks later. In the remaining five cases bleeding recurred soon after discontinuance of balloon tamponade and in these cases the operation was carried out as an emergency. Before surgery each patient was assigned to one of three categories according to a combination of clinical and biochemical criteria (table II). 
TABLE I-Clinical and Biochemical Data

\begin{tabular}{|c|c|c|c|c|c|c|c|c|}
\hline $\begin{array}{l}\text { Case } \\
\text { No. }\end{array}$ & $\underset{\text { (Years) }}{\text { Age }}$ & Sex & Diagnosis & $\underset{(\mathrm{mg} / 100 \mathrm{ml})}{\underset{\text { Serum }}{\text { Silirubin }}}$ & $\begin{array}{c}\text { Serum } \\
\text { Albumin } \\
(\mathrm{g} / 100 \mathrm{ml})\end{array}$ & $\begin{array}{c}\text { Prothrombin } \\
\text { Time } \\
\text { (Seconds) } \\
\text { (Prolonged) }\end{array}$ & Grade & Outcome \\
\hline $\begin{array}{r}1 \\
2 \\
3 \\
4 \\
5 \\
6 \\
7 \\
8 \\
9 \\
10 \\
11 \\
12 \\
13 \\
14 \\
15 \\
16 \\
17 \\
18 \\
19 \\
20 \\
21 \\
22 \\
23 \\
24\end{array}$ & $\begin{array}{l}41 \\
57 \\
42 \\
52 \\
56 \\
54 \\
49 \\
29 \\
52 \\
52 \\
72 \\
38 \\
34 \\
51 \\
63 \\
50 \\
42 \\
31 \\
36 \\
50 \\
52 \\
44 \\
56 \\
53\end{array}$ & $\begin{array}{l}\text { M. } \\
\text { F. } \\
M . \\
M . \\
\text { F. } \\
\text { F. } \\
\text { M. } \\
\text { F. } \\
\text { M. } \\
\text { M. } \\
\text { F. } \\
\text { M. } \\
\text { F. } \\
\text { M. } \\
\text { F. } \\
\text { M. } \\
\text { M. } \\
\text { M. } \\
M . \\
M . \\
M .\end{array}$ & $\begin{array}{l}\text { Cryptogenic cirrhosis } \\
\text { Primary biliary cirrhosis } \\
\text { Alcoholic cirrhosis } \\
\text { Cryptogenic cirrhosis } \\
\text { Haemochromatosis } \\
\text { Primary biliary cirrhosis } \\
\text { Alcoholic cirrhosis } \\
\text { Cryptogenic cirrhosis } \\
\text { Active chronic hepatitis } \\
\text { Alcoholic cirrhosis } \\
\text { Cryptogenic cirrhosis } \\
\text { Active chronic hepatitis } \\
\text { Active chronic hepatitis } \\
\text { Active chronic hepatitis } \\
\text { Active chronic hepatitis } \\
\text { Alcoholic cirrhosis } \\
\text { Alcoholic cirrhosis } \\
\text { Alcoholic cirrhosis } \\
\text { Alcoholic cirrhosis } \\
\text { Cryptogenic cirrhosis } \\
\text { Alcoholic cirrhosis } \\
\text { Alcoholic cirrhosis } \\
\text { Primary biliary cirrhosis } \\
\text { Alcoholic cirrhosis }\end{array}$ & $\begin{array}{r}1 \cdot 0 \\
1 \cdot 4 \\
0.9 \\
3 \cdot 8 \\
1 \cdot 0 \\
2 \cdot 0 \\
1 \cdot 6 \\
0 \cdot 7 \\
3 \cdot 5 \\
1.5 \\
1 \cdot 6 \\
3.5 \\
2 \cdot 4 \\
2 \cdot 1 \\
14 \cdot 0 \\
3.9 \\
3 \cdot 2 \\
1 \cdot 1 \\
1.9 \\
1 \cdot 1 \\
2 \cdot 0 \\
1.9 \\
1.9 \\
3 \cdot 6\end{array}$ & $\begin{array}{l}3 \cdot 5 \\
2 \cdot 8 \\
3 \cdot 5 \\
2 \cdot 0 \\
3 \cdot 8 \\
3 \cdot 4 \\
2 \cdot 7 \\
3 \cdot 7 \\
3 \cdot 6 \\
3 \cdot 1 \\
2 \cdot 5 \\
3 \cdot 8 \\
3 \cdot 0 \\
2 \cdot 3 \\
2 \cdot 2 \\
3 \cdot 2 \\
3 \cdot 4 \\
3 \cdot 7 \\
3 \cdot 8 \\
3 \cdot 5 \\
2 \cdot 8 \\
2 \cdot 9 \\
4 \cdot 1 \\
4 \cdot 2\end{array}$ & $\begin{array}{l}9 \\
3 \\
3 \\
3 \\
3 \\
0 \\
3 \\
3 \\
0 \\
1 \\
7 \\
5 \\
2 \\
7 \\
3 \\
5 \\
3 \\
3 \\
1 \\
2 \\
6 \\
1 \\
3 \\
0 \\
7\end{array}$ & $\begin{array}{l}\text { A } \\
\text { B } \\
\text { A } \\
\text { C } \\
\text { A } \\
\text { A } \\
\text { B } \\
\text { B } \\
\text { B } \\
\text { B } \\
\text { C } \\
\text { B } \\
\text { B } \\
\text { C } \\
\text { C } \\
\text { B } \\
\text { A } \\
\text { A } \\
\text { A } \\
\text { A } \\
\text { B } \\
\text { A } \\
\text { A } \\
\text { B }\end{array}$ & 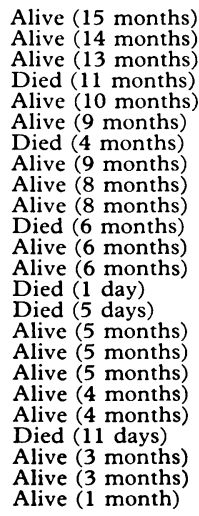 \\
\hline
\end{tabular}

TABLE II-Grading of Patients according to Severity of Liver Disease Assessed both Clinically and on Laboratory Tests into Categories A (5-6 Points), $B$ (7-9 Points), and $C$ (10 Points and Over)*

\begin{tabular}{|c|c|c|c|}
\hline \multirow[t]{2}{*}{ Clinical/Laboratory Measurements } & \multicolumn{3}{|c|}{$\begin{array}{c}\text { Points Scored for Increasing } \\
\text { Abnormality }\end{array}$} \\
\hline & 1 & 2 & 3 \\
\hline 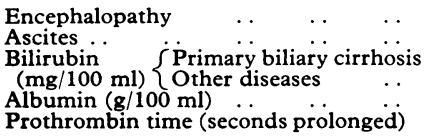 & $\begin{array}{c}\text { None } \\
\text { Absent } \\
1-4 \\
1-2 \\
3.5 \\
1-4\end{array}$ & $\begin{array}{l}\text { Grades } 1 \text { and } 2 \\
\text { Slight } \\
>4-10 \\
>2-3 \\
2 \cdot 9-3 \cdot 4 \\
4-6\end{array}$ & $\begin{array}{c}\text { Grades } 3 \text { and } 4 \\
\text { Moderate } \\
>10 \\
>3 \\
2 \cdot 8 \\
6\end{array}$ \\
\hline
\end{tabular}

*Adapted from Pugh et al. (1973).

\section{Surgical Procedure}

The abdomen is opened through a long midline incision. The transverse mesocolon is lifted up and the superior mesenteric vein identified in the root of the small-bowel mesentery as it crosses the third part of the duodenum. The pulsation of the superior mesenteric artery acts as a guide to the left margin of the vein. In obese patients and those with dilated lymphatics or fleshy lymph nodes this dissection can be tedious and difficult. An adequate length of the superior mesenteric vein is cleanly dissected to expose its anterior, right lateral, and posterior aspects.

The inferior vena cava is next dissected out, beginning at the point where it is crossed by the third part of the duodenum. An adequate length of caval wall $(5-8 \mathrm{~cm})$ is exposed to allow the application of a Satinsky clamp so that the graft can be inserted into the cava just below the inferior border of the duodenum. A Dacron graft (No. 14 or 16) is anastomosed to the cava using a continuous $5 / 0$ polypropylene suture. To avoid tearing the vein wall the needle is always inserted through the graft first. This is most easily accomplished by the surgeon moving to the opposite side of the operating table for half of the anastomosis. The graft is preclotted and the anastomosis checked for leaks, after which a small De Bakey clamp is placed across the graft almost flush with the cava.

The graft is then filled with heparinized saline and brought through a peritoneal window to lie alongside the superior mesenteric vein. The graft is trimmed and the superior mesenteric vein is occluded by a small Satinsky clamp. The graft is then anastomosed to the right posterolateral aspect of the vein, the posterior row of sutures being completed from within the lumen. Great care must be taken not to tear the thin wall of the mesenteric vein. Before the last few sutures are inserted more heparinized saline is put into the graft to get rid of any remaining air. Both clamps are removed after completion of the anastomosis. Flow through the graft is easily confirmed by feeling a fluid thrill on gently squeezing the graft. A small steel stitch may be put on to the peritoneum adjacent to the caval end of the graft to facilitate subsequent radiological demonstration of shunt patency.

\section{Results}

\section{MORTALITY}

Three of the five patients in whom the procedure was carried out as an emergency were in category B and two were in category C. One of the latter, a 63-year-old woman with active chronic hepatitis (case 15), lapsed into deep hepatic coma and died 48 hours after surgery. The remaining four patients left hospital alive and well.

Of the 19 patients undergoing an elective operation 10 were in category A, seven were in category $B$, and two were in category $\mathrm{C}$ (poor risk). Two deaths occurred during the postoperative period. The first was in a 51 -year-old man (case 14) in category $\mathrm{C}$ with active chronic hepatitis who developed a severe haemorrhagic diathesis within hours of the operation. The other fatality was due to septicaemia developing five days after operation in a 52-year-old man (case 21) in category $\mathrm{B}$ with severe alcoholic cirrhosis. The remaining 17 patients made a good postoperative recovery and were able to leave hospital. Thus the hospital mortality in the patients having an elective operation was $11 \%$, though when operative risk is related to classification before surgery it is seen that none of those in category A died.

Of the 21 patients discharged from hospital three subsequently died. Recurrent haemorrhage four months after the operation was responsible in one category B case (see below). The other two patients (cases 11 and 4), both with cryptogenic cirrhosis and in category $\mathrm{C}$, died from hepatic failure at 6 and 11 months respectively. At the time of writing none of the good-risk (category A) patients had died but the overall mortality rate in the moderate-risk (category B) and poorrisk (category C) cases was high, two out of 10 patients and four out of four patients, respectively, having died, within one year of the operation.

\section{REBLEEDING AND PATENCY OF SHUNT}

Among the 21 patients surviving the operative period there were two instances of further gastrointestinal haemorrhage. The first was in a 50-year-old man with alcoholic cirrhosis (case 16) who suffered a massive haematemesis five months after the operation. This was shown to be from a duodenal ulcer and he subsequently underwent a successful partial gastrectomy. The second was in a 49-year-old woman (case 7), also with alcoholic cirrhosis, who four months after an emergency mesocaval shunt operation had repeated haematemeses which finally proved fatal. At necropsy there was an extensive erosive gastritis as well as a single oesophageal varix though the Dacron graft was patent. 
Serial barium-swallow examinations were performed in 19 patients. In 15 the varices could be seen to be reduced in size and in a further three the varices were no longer demonstrable. In one patient (case 10) variceal size had not changed up to eight months after surgery though portal pressure was shown to have fallen at operation and there was no recurrence of bleeding.

Direct visualization of the shunt was attempted in two ways. Combined coeliac and mesenteric axis angiography with subtraction techniques to examine the venous phase showed early filling of the vena cava (suggesting a patent shunt) in two of the four cases in which it was attempted though the graft itself could not be seen. In one of the cases with early vena caval filling intrahepatic branches of the portal vein were also seen. A simpler technique and one causing little discomfort to the patient proved to be direct cannulation of the graft using a catheter introduced into the inferior vena cava via the femoral vein (see fig.). This procedure is greatly facilitated if a radio-opaque marker is left by the caval anastomosis at the time of surgery.

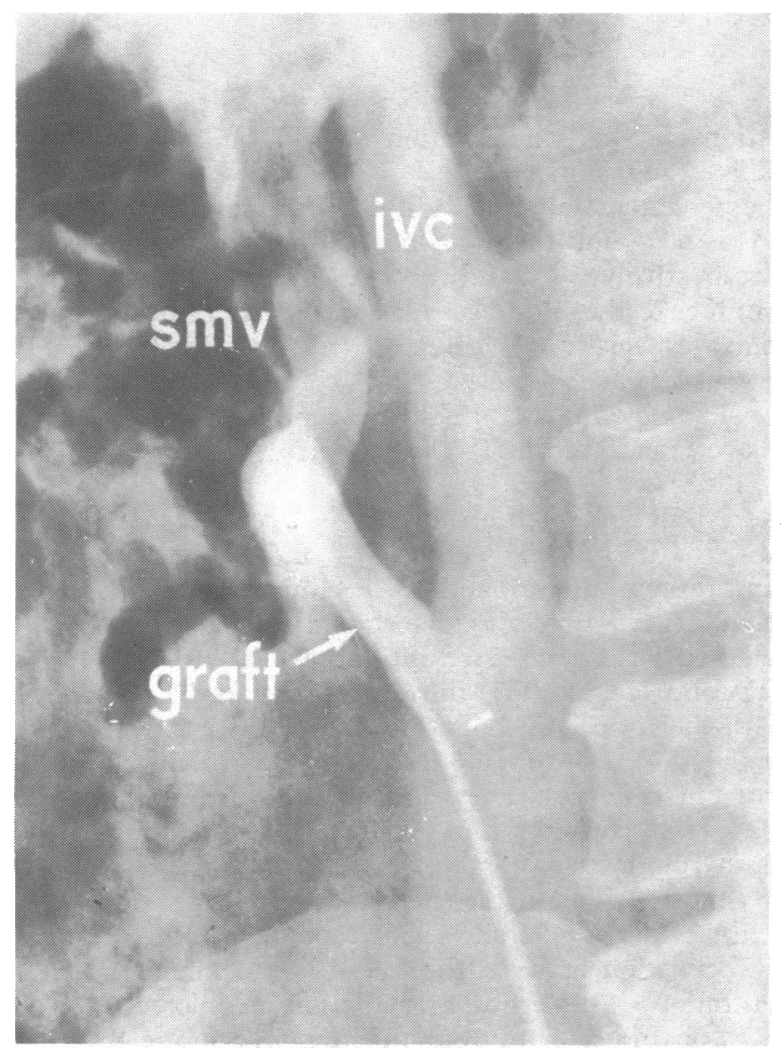

Catheter introduced into jump graft via femoral vein. Most contrast medium has passed into inferior vena cava (ivc) a little has refluxed into superior mesenteric vein (smv).

Using one or other of these methods we obtained direct or indirect evidence of shunt patency in 20 of the 21 patients discharged from hospital (the one exception, case 10, being referred to above). At five of the six necropsies the graft was found to be free from thrombus, the single exception being in the patient (case 21) who died from septicaemia within two weeks after surgery.

\section{POSTOPERATIVE ENCEPHALOPATHY}

The patients were divided into three groups before surgery on the basis of the Reitan trail test, physical examination, and analysis of the E.E.G. as follows: those with no evidence of encephalopathy, those with moderate encephalopathy easily controlled by neomycin and protein restriction, and those who were frankly encephalopathic despite such measures. Assessment three months after surgery showed that only three of the 20 patients $(15 \%)$ so tested had deteriorated. In each case the deterioration was from no evidence of encephalopathy to the moderate category.

\section{Discussion}

These results confirm the experience of Drapanas (1972) that the mesocaval shunt provides an efficient means of lowering portal hypertension. Preoperative splenic venography was not practised in this series as we have never encountered a case of superior mesenteric vein occlusion in cirrhosis. Indeed, a mesocaval shunt was satisfactorily achieved in one of our patients in whom portacaval anastomosis had to be abandoned because of a thrombosed portal vein. In extrahepatic portal vein thrombosis without cirrhosis, however, peroperative venography through a jejunal vein should be done before beginning the dissection as we have seen two such patients in whom the superior mesenteric vein was replaced by a leash of collaterals. Fears that inclusion of the synthetic Dacron would predispose to thrombosis did not materialize and it was not necessary to test the practicability of replacing an occluded shunt.

The operative mortality for emergency surgery in category $B$ and $\mathrm{C}$ patients found by Drapanas (30\%) compares favourably with the frequently quoted figure of $50 \%$ for emergency end-toside portacaval surgery (Orloff, 1967). This, he suggested, may be due to the shorter operating time for the mesocaval shunt compared with standard portacaval surgery. The mortality rate for emergency operations in our series was also low but the numbers were small, and in our experience the operating time required is much the same as for an end-to-side portacaval anastomosis. The possibly different effects of these various shunts on hepatic haemodynamics is less certain. Turcotte et al. (1969) found in a series of 102 patients that side-to-side portacaval shunts were associated with a lower operative mortality than the end-to-side variety, especially in the poor-risk cases. With mesocaval shunts as with other side-to-side shunts some hepatopetal portal blood flow may be preserved, as was readily shown by Drapanas in his patients on postoperative arteriography and confirmed in one case in the present series.

All four of our category $C$ patients died within one year after the operation and it must at least be questioned whether such patients should ever be treated by a shunt operation. Unfortunately when there is poor liver function other surgical procedures designed to arrest and prevent variceal bleeding also have a crippling operative mortality. In such cases operation should be delayed for as long as possible to allow liver function to improve. This is particularly important in cases of alcoholic liver disease with an acute hepatitis superimposed on cirrhosis. Case 18 in the present series fell clearly into category $\mathrm{C}$ when first assessed on admission to hospital, scoring 14 points on the basis of marked jaundice (serum bilirubin $8 \mathrm{mg} / 100 \mathrm{ml}$ ), gross ascites, moderate encephalopathy, a prolonged prothrombin time (by 8 seconds), and a low serum albumin $(1.9 \mathrm{~g} / 100 \mathrm{ml})$. Fortunately bleeding did not recur once the Sengstaken-Blakemore tube was removed and five weeks later liver function had improved to such an extent that the patient was reclassified into category $A$ and subsequently underwent a successful mesocaval shunt operation. The potential for such improvement in liver function with abstinence may in part account for the disparity between our findings and the long-term results obtained by Drapanas in the poor-risk cases. Whereas most of his patients were alcoholics our category $\mathrm{C}$ patients had either cryptogenic 
cirrhosis or active chronic hepatitis and their subsequently rapid downhill course may have been more of a reflection of the underlying disease.

In contrast the results in our patients with good or moderate liver function before elective surgery were very satisfactory. To verify whether this side-to-side shunt does afford a significant reduction in hepatic encephalopathy as compared with an end-to-side portacaval anastomosis while maintaining satisfactory long-term protection from haemorrhage it would be necessary to set up a prospective controlled trial. Such a trial would certainly need to be on a multicentre basis, a somewhat daunting prospect when one considers all the prob- lems encountered in the various American trials of portacaval anastomosis.

\section{References}

Callow, A. D., et al. (1970). Surgery, 67, 97

Drapanas, T. (1972). Annals of Surgery, 176, 435.

Jackson, F. C., et al. (1971). Annals of Surgery, 174, 672

Jackson, F. C., et al. (1971). Annals of Surger

Orloff, M. J. (1967). Annals of Surgery, 166, 456.

Pugh, R. N. H., et al. (1973). British Fournal of Surgery, 60, 646.

Turcotte, J. G., Wallin, V. W., and Child, C. G., (1969). American fournal of Surgery, 117, 108.

Warren, W. D., Zeppa, K., and Fomon, J. J. (1967). Annals of Surgery, 166,437 .

\title{
Comparison between Determination of Free Thyroxine Index and Effective Thyroxine Ratio in Human Serum
}

\author{
E. G. M. D'HAENE， F. J. L. CROMBAG， J. F. W. TERTOOLEN
}

British Medical fournal, 1974, 3, 708-711

\section{Summary}

Four thyroid function indices were determined in the sera of 181 patients: total thyroxine ( $T-4)$, the triiodothyronine resin uptake (T-3 B.C.-index), the free thyroxine (T-4) index, and the effective thyroxine ratio (E.T.R.).

A statistically significant correlation between the free T-4 index and E.T.R. could be established though this correlation seemed to be worse than could be expected from the literature. Two sets of correlation coefficients were shown: one obtained with the ordinarily used Pearson or product-moment correlation and one with the Spearman rank correlation. Because the assumptions and requirements for the proper use of the productmoment correlation statistics, such as a normal distribution of both variables, are seldom met, expecially not if a selected number of controls and patients is used for the correlation, it is advisable to use some kind of rank correlation statistics instead.

The advantages and disadvantages of the E.T.R. and free $T-4$ index determination are described.

\section{Introduction}

There are many in-vitro methods now used to determine thyroid function, of which the estimation of total thyroxine $(T-4)$ in serum based on competitive protein-binding analysis introduced by Ekins (1960) seems to be increasingly accepted as a specific and reliable procedure. A good correlation between serum T-4 concentration and thyroid function has been shown (Murphy et al., 1966). An important objection to this method is that

Clinical Chemistry Laboratory, Municipal Hospital, Dordrecht E. G. M. D'HAENE, PH.D., Clinical Chemist

Clinical Chemistry Laboratory, Hospital St. Annadal, Maastricht

F. J. L. CROMBAG, PH.D., Clinical Chemist (Present address: Maasziekenhuis, Boxmeer, The Netherlands)

"Voorburg," Vught, The Netherlands

J. F. W. TERTOOLEN, Radiochemist alterations in the concentration of $\mathrm{T}-4$ binding proteins may invalidate the results.

The percentage binding of $\mathrm{T}-4$ to thyroxine-binding globulin (TBG) is $60 \%$ and to thyroxine-binding prealbumin and albumin, respectively, $30 \%$ and $10 \%$. A variety of diseases and drugs may influence the binding capacity and concentration of these proteins, especially of TBG (Selenkow and Ingbar, 1970). As a consequence of raised TBG concentration, for instance, euthyroid women taking oral contraceptives or pregnant women may have a raised serum T-4 level (Murphy et al., 1966; Goolden et al., 1967).

The estimation of the true free $\mathrm{T}-4$ concentration gives the quantity of hormonally active T-4 and is not influenced by binding-protein abnormalities. Technical difficulties are the principal reason why this determination has been considered only as a research procedure until now.

Clark and Horn (1965) introduced the free T-4 index: they divided their protein bound iodine (P.B.I.) results by the respective $\mathrm{T}-3$ resin uptake values, thus correcting for bindingprotein abnormalities. They showed that this index was proportional to the concentration of free $T-4$, assuming that this triiodothyronine resin uptake (T-3 B.C. index) was proportional to the concentration of free sites on $\mathrm{T}-4$ binding proteins.

Wellby and O'Halloran (1966) reported a highly significant linear correlation between the free $\mathrm{T}-4$ index and the free $\mathrm{T}-4$ concentration. They showed the usefulness of the free T-4 index as an index of thyroid function in routine diagnosis in patients having binding-protein abnormalities. To get this free T-4 index, however, one has to carry out two separate determinations for total T-4 (or P.B.I.) and for T-3 B.C. index.

Recently Thorson et al. (1972) described a new in-vitro test for the determination of thyroid status, which they called the effective thyroxine ratio (E.T.R.).* The authors claim that this test has a high diagnostic accuracy $(99 \%)$ and that the results are proportional to the free T-4 concentration. Wellby et al. (1973) studied 76 patient sera and reported a linear relationship $(r=0.93)$ between E.T.R. and free T-4 concentration. This could be confirmed by others (Rudorff et al., 1973).

Because we were interested to know whether this rapid single procedure could replace our more time-consuming free $\mathrm{T}-4$ index determination we compared the results of E.T.R. and free $\mathrm{T}-4$ index determinations from the sera of 181 patients.

*E.T.R. and ResOmat are registered trade marks of Mallinckrodt Chemical Works, St. Louis, Missouri, U.S.A. 